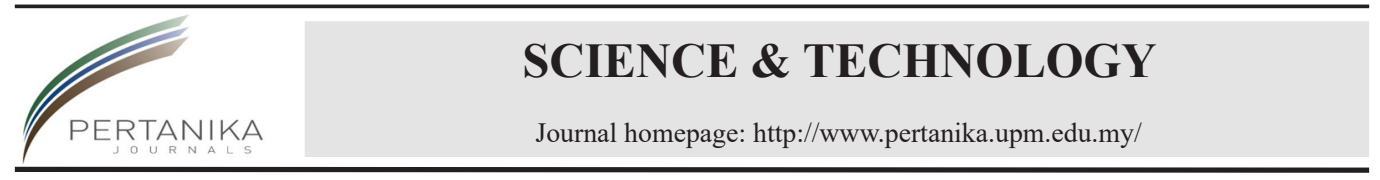

\title{
Synthesis and Performance of PAFS Coagulant Derived from Aluminium Dross
}

\author{
Shiyi Li ${ }^{1}$ and Shafreeza Sobri ${ }^{1,2 *}$ \\ ${ }^{1}$ Department of Chemical and Environmental Engineering, Faculty of Engineering, Universiti Putra Malaysia, \\ 43400 UPM, Serdang, Selangor, Malaysia \\ ${ }^{2}$ Institute of Advanced Technology, Universiti Putra Malaysia, 43400 UPM Serdang, Selangor, Malaysia
}

\begin{abstract}
Polymerised aluminium ferric sulphate (PAFS) was prepared from aluminium dross as a coagulant in wastewater treatment. The effects of leaching time, leaching temperature, and sulfuric acid concentrations on the turbidity removal of the wastewater were investigated, and the optimum conditions were determined using response surface methodology. The results showed that the optimum PAFS preparation conditions were at a leaching time of 60 minutes, a leaching temperature of $65^{\circ} \mathrm{C}$, and a sulfuric acid concentration of $1 \mathrm{~mol} / \mathrm{L}$. Furthermore, experiments were performed to investigate the effect of coagulant dosages using the PAFS prepared under the optimum leaching conditions, settling time and initial $\mathrm{pH}$ of the wastewater on the turbidity removal efficiency. As a result, it was found that the optimum coagulation conditions for PAFS coagulants were at a settling time of 15 minutes, coagulant dosage of $0.5 \mathrm{~g}$, and raw water $\mathrm{pH} 8$. Under these optimum conditions, the turbidity removal efficiency of the wastewater was $91.45 \%$. The purpose of this study was to investigate the possibility of aluminium dross utilisation as a coagulant agent for wastewater treatment. Therefore, it can be concluded that PAFS prepared by leaching metal oxides from aluminium dross is an effective wastewater coagulant.
\end{abstract}

ARTICLE INFO

Article history:

Received: 28 June 2021

Accepted: 13 October 2021

Published: 10 January 2022

DOI: https://doi.org/10.47836/pjst.30.1.30

E-mail addresses:

eng.ziva@foxmail.com (Shiyi Li)

shafreeza@upm.edu.my (Shafreeza Sobri)

*Corresponding author
Keywords: Aluminium dross, PAFS coagulant, response surface methodology, turbidity

\section{INTRODUCTION}

Recent developments in the transportation and construction industries, the rapid growth of cities, and the discovery of new potential uses have strengthened the position of aluminium as a key structural material. However, the increasing demand 
for aluminium in the coming decades will also release a large proportion of wastes in the form of gaseous emissions and solid residue (Adeosun et al., 2014; Tsakiridis et al., 2013). For example, in 1990, about 28 million tons of aluminium metal were produced globally, but only 8 million tons of scrap were recovered, and in 2010, 56 million tons of aluminium metal were produced, and only 18 million tons of scrap were recovered (Mahinroosta \& Allahverdi, 2018). It was estimated that in 2020, global demand for aluminium was 97 million tonnes, and nearly 31 million tons of scrap will need to be recycled.

Aluminium dross is some impure mixed metal produced during the aluminium smelting and contains many aluminium oxides, iron oxides, and other metal oxides. The dross is found to be toxic and hazardous to the environment. Therefore, effective disposal of aluminium dross has become an urgent issue for the aluminium industry worldwide, and abundant work has been done on the separation and recycling of the waste product to reduce the burden of toxic liabilities (Mahinroosta \& Allahverdi, 2018; Das et al., 2006).

The current aluminium dross treatment involves the separation of the residual aluminium metal from the aluminium oxide, which can recover between 5\%-15\% of the initial content and then the waste aluminium dross will be landfilled (Adeosun et al., 2014). However, the landfilled dross can cause leaching of the toxic metals into groundwater, causing pollution of the soil and water resources (Das et al., 2006; Adeosun et al., 2014), heavy metal poisoning of surrounding residents (Xiao et al., 2005; Adeosun et al., 2014), soil salinisation, many crop deaths, and serious environmental pollution. Besides, the reactivity of the leached dross with water results in the formation of flammable gases such as ammonia, hydrogen, and methane (Tsakirids et al., 2013; Murayama et al., 2012).

Vast attention has been given to finding potential applications and resource reutilisation of aluminium dross. Pepper et al. (2016) studied extraction efficiencies of different acids in the recovery of iron and aluminium from red mud, while Rivera et al. (2018) investigated the extraction of aluminium using a dry digestion method followed by water leaching. A study by Mahinroosta and Allahverdi (2018) extracted alumina nanopowder with 97\% purity, suitable for catalytic and adsorption applications. David and Kopac (2013) managed to leach alumina from the dross using sulfuric acid, and the purity of alumina is as high as $99 \%$.

In cement and concrete technology, the substitution of aluminium dross for sand as a filler to produce bricks and other building materials can improve the stiffness and stability of the material (Kim et al., 2010). The use of aluminium dross also increases the compressive strength and porosity of cement as a raw starting material for construction and delays the setting time of concrete (Elinwa \& Mbadike, 2011; Mailar et al., 2016; Reddy \& Neeraja, 2016; Dai \& Apelian, 2016). In addition, the oxide compounds, such as aluminium oxide and magnesium oxide, have great potential as industrial grade refractories (Li et al., 2014).

Many researchers have explored the possibility of using aluminium dross as a coagulant agent in water and wastewater treatment and found that it has excellent coagulation 
behaviours (Mahinroosta \& Allahverdi, 2018; Mavinkattimath et al., 2017). The dross was dissolved in different acidic solutions to produce different coagulants, such as polymeric aluminium chloride (PAC) (Lei et al., 2009), polymeric ferric aluminium chloride (PAFC) (Yan et al., 2016; Cao et al., 2015; Zhang et al., 2015a; Gao et al., 2019), poly-ferric sulphate (PFS) (Liang et al., 2020) and poly-aluminium ferric sulphate (PAFS) (Chen et al., 2020).

PAFS is developed based on poly-ferric sulphate and poly-aluminium sulphate (Chen et al., 2020). It is mainly trivalent aluminium, supplemented by trivalent iron as an inorganic polymer coagulant formed by cross-hydrolysis and polymerisation (Jiang \& Zhu, 2021). Aluminium salt coagulants produce large flocs; however, they have difficulty settling and creating high wastewater turbidity. On the other hand, iron salt coagulants are dense and easy to settle (Yang et al., 2019). The combination effect of aluminium and iron salts in PAFS has the advantages of high base degree, large alum bloom, fast coagulation and sedimentation, low dosage, high removal rate, and wide application fields (Zhang et al., 2015a). It also overcomes the poly-aluminium biological toxicity of the coagulant and solves the shortcomings of unclear water and the high colour of the poly-ferric coagulant (Mohd-Salleh et al., 2020; Zhu et al., 2011; Sun et al., 2012).

In this study, the composite coagulant polymeric aluminium ferric sulphate was synthesised by leaching alumina and iron oxide from aluminium dross with different concentrations of sulfuric acid at different temperatures and times. In order to optimise the performance of the polymeric aluminium ferric sulphate, a response surface methodology was used to investigate the interaction between the individual factors and obtain the optimum synthesis conditions. Finally, the optimal coagulation performance of the PAFS coagulant was investigated by studying the effects of wastewater $\mathrm{pH}$, coagulant dosage, and settling time. This study focuses on the acid leaching-based route of aluminium oxide extraction for use as a coagulant agent in wastewater treatment. Studies on treatment and retrieval processes of aluminium dross will reduce the burden of aluminium production industries in terms of waste generation, disposal cost, and environmental pollution by turning hazardous industrial waste into wealth.

\section{METHODOLOGY}

\section{Chemical Characterization of Aluminium Dross}

The aluminium dross sample was obtained from a waste management company in Malaysia. The sample was stored in a sealed polyethene container. The chemical properties of the aluminium dross were determined by X-ray fluorescence (XRF).

\section{Preparation of PAFS Coagulant}

PAFS coagulant was prepared using analytical grade sulfuric acid $\left(\mathrm{H}_{2} \mathrm{SO}_{4}\right)$, sodium 
hydroxide $(\mathrm{NaOH})$, and dipotassium hydrogen phosphate $\left(\mathrm{K}_{2} \mathrm{HPO}_{4}\right)$. All solutions were prepared using deionised water.

$10 \mathrm{~g}$ of raw aluminium dross was leached using sulfuric acid with different molarities $(0.5 \mathrm{~mol} / \mathrm{L}-2.5 \mathrm{~mol} / \mathrm{L})$ in a $250 \mathrm{ml}$ beaker. The beaker was placed on a hot plate with a magnetic stirrer, and the temperature was varied between $50^{\circ} \mathrm{C}$ to $100^{\circ} \mathrm{C}$. The leaching duration was set between 60 minutes to 120 minutes, and a stirring speed of $350 \mathrm{rpm}$ was used for all experimental works. First, the experimental data were submitted to regression analysis to predict a significant relationship between the data points. Then, the leached solution was filtered using vacuum pumps, followed by washing with deionised water to wash off the precipitates. Next, $0.35 \mathrm{~g}$ dipotassium phosphate was added to the filtrate. After 10 minutes, sodium hydroxide solution is added to adjust the $\mathrm{pH}$ to 1.5. After stirring for 1 hour at $65^{\circ} \mathrm{C}$ and ageing for more than 24 hours at room temperature, a liquid PAFS coagulant was obtained. Finally, the liquid coagulant was dried at $60^{\circ} \mathrm{C}$ for several days to obtain a solid coagulant.

\section{Wastewater Collection}

The wastewater was collected from a lake located at the Faculty of Engineering, Universiti Putra Malaysia, using the grab sampling method. The lake water was collected in glass bottles that were earlier washed with dilute soap water, followed by double distilled water. The chemical analysis of the wastewater showed that the $\mathrm{pH}$ value and turbidity were within the ranges of 6.0-7.0 and 14.4-26.8 NTU, respectively.

\section{Optimisation of Leaching using RSM}

Based on the results of the single-factor experiments, Design-Expert software and RSM Box-Behnken Design were used to investigate further the effects of leaching time, leaching temperature, and sulfuric acid concentrations on the turbidity removal. Fourteen sets of experiments were created using Box Behnken Design (BBD). Model applicability was assessed by analysis of variance and significance tests.

\section{Turbidity Removal Test}

PAFS coagulant was prepared under the optimum leaching conditions obtained from experimental and optimisation studies. Coagulation experiments were performed using the jar test method to study the effect of wastewater $\mathrm{pH}(5-10)$, coagulant dosages ( 0.1 grams -0.5 grams) and settling time ( 5 minutes -25 minutes) on turbidity removal efficiencies. The experimental data were submitted to regression analysis to predict a significant relationship between the data points. $300 \mathrm{~mL}$ of a mixture of wastewater and coagulant was rapidly stirred at $300 \mathrm{rpm}$ for 30 seconds. Then, the mixture was stirred at 
$170 \mathrm{rpm}$ for two minutes, followed by $50 \mathrm{rpm}$ for five minutes, and left to settle for 10 minutes. Samples for turbidity measurement were extracted from $2 \mathrm{~cm}$ below the water surface in the beaker. The turbidity removal efficiency was calculated using Equation 1.

$$
\operatorname{TRE}=\frac{\left(T_{0}-T\right)}{T_{0}} \times 100 \%
$$

Where:

$\mathrm{T}_{\mathrm{o}}$ : Initial turbidity of raw wastewater, NTU

T: Turbidity of coagulated wastewater, NTU

\section{RESULT AND DISCUSSION}

\section{Chemical Composition of Aluminium Dross}

Aluminium dross contains a large number of metal oxides with large proportions of aluminium oxides, $\mathrm{Al}_{2} \mathrm{O}_{3}$. As shown in Table $1, \mathrm{Al}_{2} \mathrm{O}_{3}$ constitutes $74.71 \%$ of the dross content. In addition, the dross contains minor amounts of oxides of other components, such as $\mathrm{Fe}_{2} \mathrm{O}_{3}, \mathrm{SiO}_{2}, \mathrm{CaO}, \mathrm{BaO}, \mathrm{CuO}$, and $\mathrm{ZnO}$. The chemical composition of aluminium dross differs from one factory to another, depending on the production operating conditions, the technology applied for the production process and the type of furnace (Mahinroosta \& Allahverdi, 2018).

Table 1

Metal oxides analysis of the Al Dross using X-ray Fluorescence (XRF)

\begin{tabular}{cccccccc}
\hline Compounds & $\mathrm{Al}_{2} \mathrm{O}_{3}$ & $\mathrm{Fe}_{2} \mathrm{O}_{3}$ & $\mathrm{SiO}_{2}$ & $\mathrm{CaO}$ & $\mathrm{BaO}$ & $\mathrm{CuO}$ & $\mathrm{ZnO}$ \\
\hline$\%$ & 74.71 & 4.41 & 6.15 & 3.46 & 5.55 & 0.23 & 0.073 \\
\hline
\end{tabular}

\section{Effect of Leaching Temperature on Turbidity Removal Efficiency}

The effect of leaching temperatures on turbidity removal efficiency is shown in Figure 1. The temperatures were chosen based on previous studies by other researchers on the effect of varying temperatures on the dissolution of alumina (Sarker et al., 2015; Feng et al., 2020; David \& Kopac, 2013). Regression analysis was performed on the experimental data, and results showed that the leaching temperature (X variable) has a significant influence on turbidity removal rate ( $\mathrm{Y}$ variable) with analysis of variance $\mathrm{P}<0.05$, and therefore $\mathrm{Y}$ variable was predicted for different temperature values.

The highest turbidity removal efficiency was found to be $80 \%$ at $75^{\circ} \mathrm{C}$ but decreased to $50 \%$ when the temperature was increased to $100^{\circ} \mathrm{C}$. Generally, the increase in temperature facilitates the reaction and extraction of alumina (Yan et al., 2016). As the reaction temperature increases, the molecular movement speeds up, and the hydrogen ion 
activity increases (Mahinroosta \& Allahverdi, 2018). As a result, it causes the solubility of aluminium to increase gradually (Su et al., 2010). However, when the temperature is too high, the water vapour inside the container is released, and the concentration of the solution rises (Zhang et al., 2019), which leads to the breakage of chemical bonds (Jiang \& Zhu, 2021; Zhang \& Ren, 2013). As a result, it causes large amounts of sulphate ions to form a new molecular layer structure, and the solubility of aluminium is reduced (Zhang et al., 2015 b), thus inhibiting the extraction of alumina. In addition, high temperatures consume much energy and increase the operating costs of the extraction process.

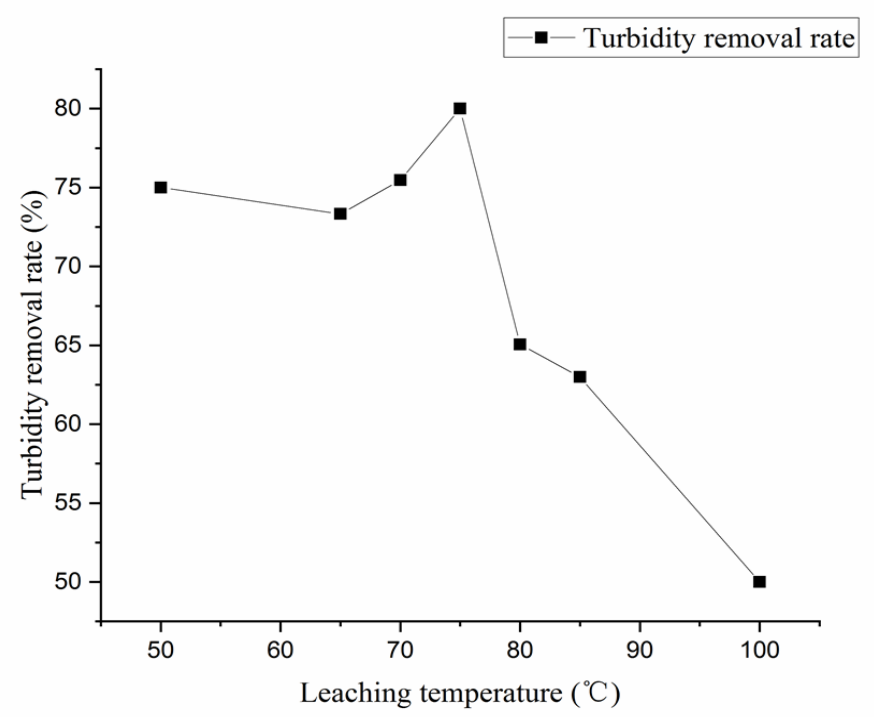

Figure 1. Effect of leaching temperature on turbidity removal efficiency (sulfuric acid concentration: $1 \mathrm{~mol} / \mathrm{L}$, leaching time: 60 minutes)

\section{Effect of Sulfuric Acid Concentrations on Turbidity Removal Efficiency}

The effect of sulfuric acid concentrations on turbidity removal efficiency is shown in Figure 2. Regression analysis was performed on the experimental data, and results showed that the sulfuric acid concentrations ( $\mathrm{X}$ variable) have a significant influence on turbidity removal rate ( $\mathrm{Y}$ variable) with analysis of variance $\mathrm{P}<0.05$, and therefore $\mathrm{Y}$ variable was predicted for different acid concentrations. It is evident that the turbidity removal efficiency showed an increasing trend from $68 \%$ at $0.5 \mathrm{~mol} / \mathrm{L}$ to $80 \%$ at $1.0 \mathrm{~mol} / \mathrm{L}$. It is due to the fact that as the sulfuric acid concentration increases, the sulphate ions increase and the diffusion of hydrogen ions accelerates (Sarker et al., 2015). Aluminium ions form negatively charged ions with sulphate ions (Cui et al., 2015), and the diffusion of aluminium ions start to accelerate (Sarker et al., 2015); thus, the solubility rate increases accordingly (David \& Kopac, 2013). 
However, the turbidity removal efficiency decreased to $35 \%$ when $2.5 \mathrm{~mol} / \mathrm{L}$ of sulfuric acid was used. When the sulfuric acid concentration is too high, the solubility of basic aluminium sulphate increases (David \& Kopac, 2013) and the aluminium ions hinder the diffusion of hydrogen ions (Sarker et al., 2015). Therefore, it causes the aluminium leaching to deteriorate, and turbidity removal becomes erratic. In addition, the liquid thickens, and the solubility of aluminium and iron sulphate decreases.

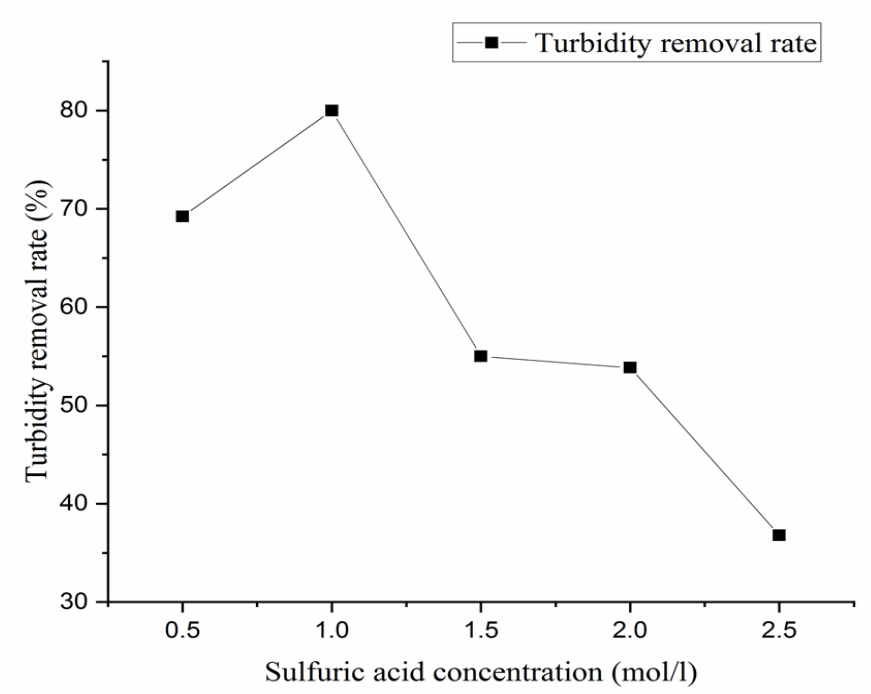

Figure 2. Effect of sulfuric acid concentrations on turbidity removal efficiency (leaching temperature: $75^{\circ} \mathrm{C}$, leaching time: 60 minutes)

\section{Effect of Leaching Time on Turbidity Removal Efficiency}

The effect of leaching time on turbidity removal efficiency is shown in Figure 3. Regression analysis was performed on the experimental data, and results showed that the leaching time ( $\mathrm{X}$ variable) has a significant influence on turbidity removal rate ( $\mathrm{Y}$ variable) with analysis of variance $\mathrm{P}<0.05$, and therefore $\mathrm{Y}$ variable was predicted for different leaching times. The time range was chosen because if the reaction time is too short, the reaction will not absorb enough heat, affecting the reaction. However, at prolonged reaction time, the water in the solution evaporates, and the filtrate becomes viscous (Chen et al., 2020), resulting in a loss of some of the leachate during filtration, causing a decrease in turbidity removal efficiency. Based on the results, the highest efficiency was $80 \%$ at 60 minutes leaching time but decreased to as low as $45 \%$ at longer leaching time. 


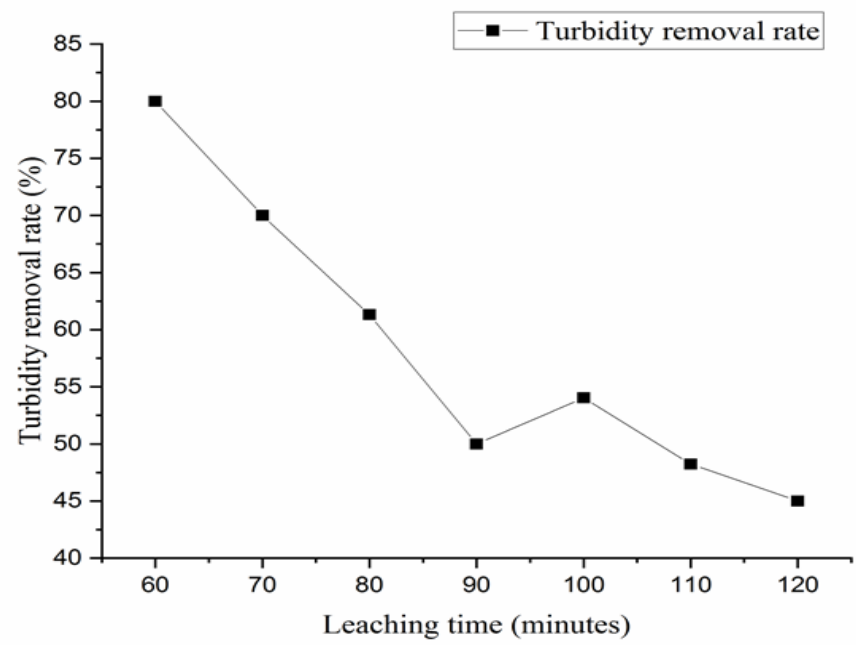

Figure 3. Effect of leaching time on turbidity removal efficiency (sulfuric acid concentration: $1 \mathrm{~mol} / \mathrm{L}$, leaching temperature: $75^{\circ} \mathrm{C}$ )

\section{Optimisation of Alumina Leaching Conditions Using RSM}

Preliminary test results had shown that the leaching temperatures, time, and sulfuric acid concentrations greatly affected the turbidity removal efficiency. Therefore, the upper and lower limit of the three variables were suitable to be chosen as limits for optimisation. The experimental design range showing the levels of the independent variables for the turbidity removal efficiency is shown in Table 2. A total of 14 runs of different conditions were generated in the design matrix. The actual experimental design matrix and results on turbidity removal efficiency are exhibited in Table 3.

Table 2

Experimental factors and levels for optimisation of alumina leaching conditions

\section{Level}

A

Sulfuric acid

\begin{tabular}{lc} 
& concentrations $(\mathrm{mol} / \mathrm{L})$ \\
\hline $\mathbf{1}$ & 0.5 \\
$\mathbf{2}$ & 1 \\
$\mathbf{3}$ & 1.5 \\
\hline
\end{tabular}

\section{Factors}

B

Leaching time (minutes)
C Leaching temperature $\left({ }^{\circ} \mathrm{C}\right)$ 50 75 100 
Table 3

Experimental design matrix and turbidity removal efficiency

\begin{tabular}{lcccc}
\hline No. & $\begin{array}{c}\text { Sulfuric acid } \\
\text { concentration } \\
\text { (mol/L) }\end{array}$ & $\begin{array}{c}\text { Leaching time } \\
\text { (minutes) }\end{array}$ & $\begin{array}{c}\text { Leaching } \\
\text { temperature }\left({ }^{\circ} \mathbf{C}\right)\end{array}$ & $\begin{array}{c}\text { Turbidity } \\
\text { removal efficiency } \\
(\%)\end{array}$ \\
\hline $\mathbf{1}$ & 1 & 90 & 50 & 79.1667 \\
$\mathbf{2}$ & 1 & 60 & 75 & 83.3333 \\
$\mathbf{3}$ & 1 & 120 & 75 & 54.1667 \\
$\mathbf{4}$ & 1 & 90 & 100 & 42.8571 \\
$\mathbf{5}$ & 1.5 & 60 & 100 & 57.1429 \\
$\mathbf{6}$ & 1.5 & 90 & 75 & 54.1667 \\
$\mathbf{7}$ & 1.5 & 90 & 75 & 66.6667 \\
$\mathbf{8}$ & 1.5 & 120 & 50 & 61.9048 \\
$\mathbf{9}$ & 1.5 & 60 & 50 & 66.6667 \\
$\mathbf{1 0}$ & 1.5 & 120 & 100 & 25.0000 \\
$\mathbf{1 1}$ & 0.5 & 60 & 75 & 69.2308 \\
$\mathbf{1 2}$ & 0.5 & 90 & 100 & 30.7692 \\
$\mathbf{1 3}$ & 0.5 & 120 & 75 & 46.1538 \\
$\mathbf{1 4}$ & 0.5 & 90 & 50 & 61.5385 \\
\hline
\end{tabular}

By considering the three independent variables, the maximum turbidity removal efficiency of $82.276 \%$ is attainable with PAFS coagulant prepared using one mol/L sulfuric acid at $65^{\circ} \mathrm{C}$ leaching temperature and 60 minutes leaching time. Table 4 summarises the optimal experimental conditions and the predicted efficiency. A validation experiment at the optimum conditions revealed that the turbidity removal efficiency was $82.353 \%$, which proved that the model is accurate and reliable for predicting optimal conditions for the preparation of PAFS. A conclusion was made based on a small error between the actual and the predicted value, less than $1 \%$.

Table 4

Optimal experimental conditions and validations

\begin{tabular}{ll}
\hline Sulfuric acid concentration $(\mathbf{m o l} / \mathbf{L})$ & $\mathbf{1 . 0 3 3}$ \\
\hline Leaching time (minutes) & 60 \\
Leaching temperature $\left({ }^{\circ} \mathbf{C}\right)$ & 64.804 \\
Predicted turbidity removal efficiency (\%) & 82.276 \\
Actual turbidity removal efficiency $(\%)$ & 82.353 \\
\hline
\end{tabular}


Analysis of variance (ANOVA) was employed using Design Expert to evaluate the model's quality statistically, and the result is depicted in Table 5. The most crucial parameter, the Fisher's ratio value ( $\mathrm{F}$ value) of the model, indicates whether any variable provides a subtle effect on the overall response. The model's F-value was 18.68, indicating that the variance of overall data in the model is 18.68 times greater than the experimental variance and proved that the variables had some effects on the response. However, interpretation of the F value alone is insufficient to determine the variables' significant effect on the response. Based on the p-value (0.0011), the model is considered significant. A p-value of less than 0.05 for the regressions indicates statistically significant model results (Yan et al., 2016). Similarly, the significance of individual terms, such as sulfuric acid concentration, leaching time, and leaching temperature, can be determined from their respective $\mathrm{p}$-value. The most significant term in the current study was $\mathrm{B}$, followed by $\mathrm{C}, \mathrm{A}^{2}, \mathrm{C}^{2}, \mathrm{~A}, \mathrm{BC}$, and $\mathrm{AC}$.

Table 5

Analysis of variance

\begin{tabular}{|c|c|c|c|c|c|}
\hline Source & $\begin{array}{l}\text { Sum of } \\
\text { squares }\end{array}$ & $\begin{array}{c}\text { Degree of } \\
\text { freedom }\end{array}$ & Mean square & F-value & p-value \\
\hline Model & 3453.21 & 7 & 493.32 & 18.68 & 0.0011 \\
\hline $\begin{array}{l}\text { A-sulfuric } \\
\text { acid } \\
\text { concentration }\end{array}$ & 239.97 & 1 & 239.97 & 9.08 & 0.0236 \\
\hline $\begin{array}{l}\text { B-leaching } \\
\text { time }\end{array}$ & 993.43 & 1 & 993.43 & 37.61 & 0.0009 \\
\hline $\begin{array}{l}\text { C-leaching } \\
\text { temperature }\end{array}$ & 682.47 & 1 & 682.47 & 25.84 & 0.0023 \\
\hline $\mathbf{A C}$ & 29.41 & 1 & 29.41 & 1.11 & 0.3320 \\
\hline BC & 187.43 & 1 & 187.43 & 7.10 & 0.0373 \\
\hline$A^{2}$ & 312.46 & 1 & 312.46 & 11.83 & 0.0138 \\
\hline $\mathrm{C}^{2}$ & 262.74 & 1 & 262.74 & 9.95 & 0.0197 \\
\hline Residual & 158.49 & 6 & 26.41 & - & - \\
\hline Lack of Fit & 80.36 & 5 & 16.07 & 0.2057 & 0.9214 \\
\hline Pure Error & 78.12 & 1 & 78.12 & - & - \\
\hline Cor Total & 3611.69 & 13 & - & - & - \\
\hline
\end{tabular}

\section{Effect of Coagulant Dosage on Turbidity Removal Efficiency}

The effect of coagulant dosages on turbidity removal efficiency is shown in Figure 4. Different doses of coagulant were added to the wastewater, and the residual turbidity of the treated water samples was measured. Regression analysis was performed on the 
experimental data, and results showed that the coagulant dosage ( $\mathrm{X}$ variable) has a significant influence on turbidity removal rate (Y variable) with analysis of variance $\mathrm{P}<0.05$, and therefore $\mathrm{Y}$ variable was predicted for different coagulant dosages.

The coagulant becomes more effective as the dosage increases. The turbidity removal efficiency reached $87 \%$ with the addition of $0.5 \mathrm{~g}$ of PAFS coagulant. It is due to the fact that the more coagulant there is, the greater the chance of collision with the particles and the easier it is for the polymer to bond with the particles (Zhu et al., 2011). During the coagulation, the charge on the surface of the particles will bridge with the coagulant (Yan et al., 2016).

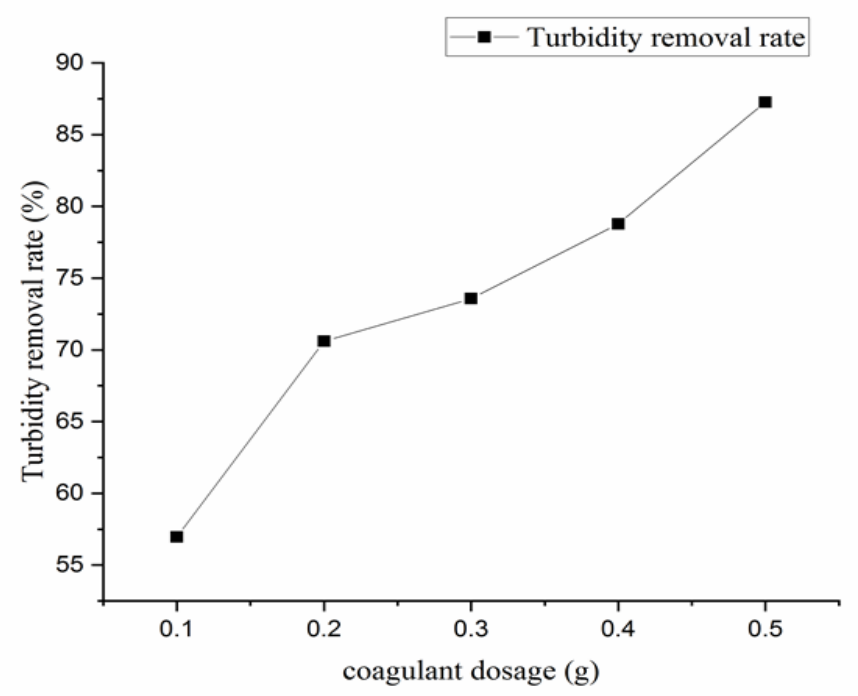

Figure 4. Effect of coagulant dosage on turbidity removal efficiency

\section{Effect of Wastewater Initial pH on Turbidity Removal Efficiency}

The $\mathrm{pH}$ of the raw water is an important parameter influencing the removal efficiency of turbidity. In this experiment, the effect of the wastewater $\mathrm{pH}$ on the coagulation effect was examined in the range of 5-10. Furthermore, regression analysis was performed on the experimental data, and results showed that the initial $\mathrm{pH}$ of the wastewater ( $\mathrm{X}$ variable) has a significant influence on turbidity removal rate ( $\mathrm{Y}$ variable) with analysis of variance $\mathrm{P}<0.05$, and therefore $\mathrm{Y}$ variable was predicted for different $\mathrm{pH}$ of the wastewater.

Figure 5 shows that the turbidity removal efficiency increased as the $\mathrm{pH}$ increased from 5 to 8 , with $86 \%$ turbidity removal at a $\mathrm{pH}$ of 8 . However, as the $\mathrm{pH}$ increased to 9 , the removal rate decreased significantly. No significant change was observed when the initial $\mathrm{pH}$ of the wastewater was increased to 10 .

Under acidic conditions, aluminium exists mainly in aluminium ions, which is not conducive to colloidal adsorption and bridging, and flocs are difficult to form (Yang et al., 
2019). However, with increasing $\mathrm{pH}$ to alkaline region, the hydrolysis of aluminium ions is accelerated, allowing for enhanced electro-neutralisation (Sun et al., 2017), resulting in more polymers and improved bridging coagulation between ions. At lower alkaline conditions, PAFS coagulants are positively charged, and both coagulants and negatively charged particulate matter are attracted to each other (Zhao et al., 2011), allowing flocs to form easily and turbidity removal to be effective. However, at higher alkaline conditions, the coagulants tend to hydrolyse too quickly (Zhao et al., 2011; Zhu et al., 2011), and the aluminium ions tend to form precipitates, which inhibits the bridging coagulation and therefore has a poor coagulation capacity (Zhao et al., 2016).

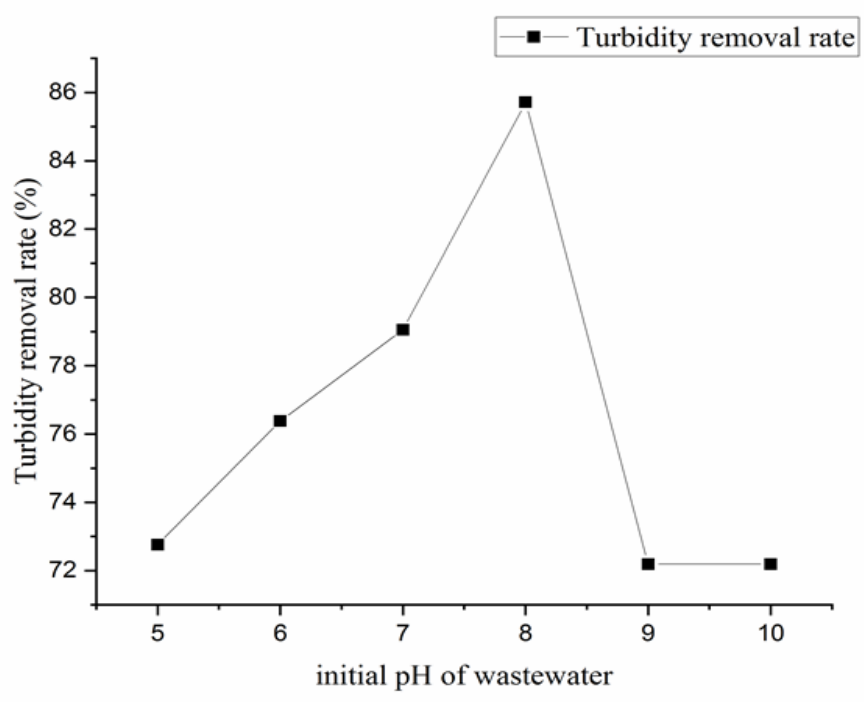

Figure 5. Effect of initial wastewater $\mathrm{pH}$ on turbidity removal efficiency

\section{Effect of Settling Time on Turbidity Removal Efficiency}

The effect of settling time on turbidity removal efficiency is shown in Figure 6. Regression analysis was performed on the experimental data, and results showed that the settling time ( $\mathrm{X}$ variable) has a significant influence on turbidity removal rate (Y variable) with analysis of variance $\mathrm{P}<0.05$, and therefore $\mathrm{Y}$ variable was predicted for different settling time - the turbidity removal efficiency increases as the settling time increases. As the settling time increases, the chance of collision between coagulants and particles increases, floc formation is complete, and turbidity removal is improved. However, the increment was less significant at a longer settling time. Therefore, 15 minutes was chosen as the optimum settling time. 


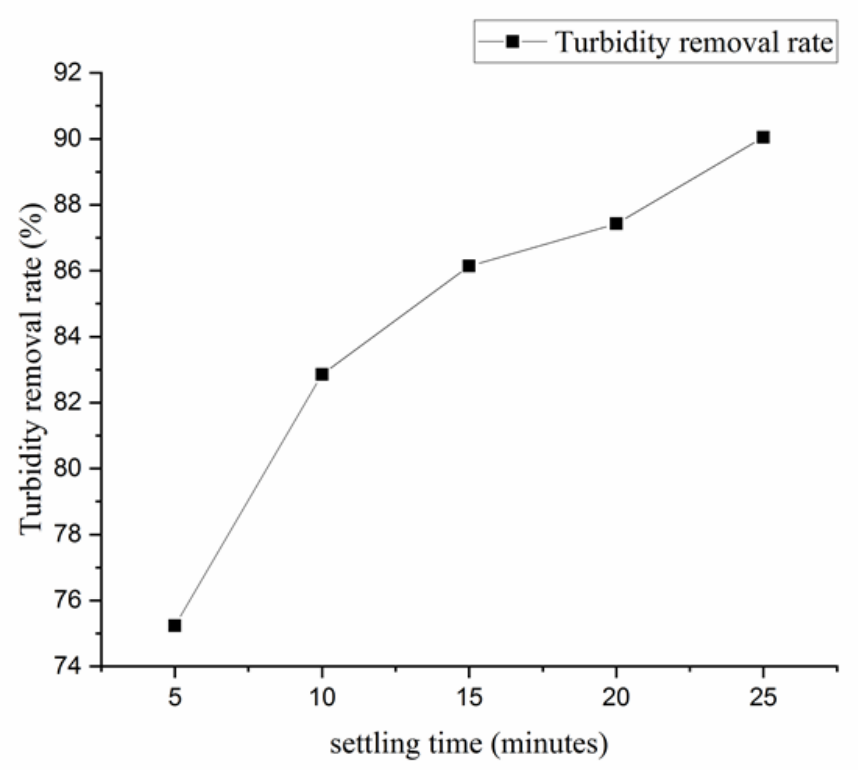

Figure 6. Effect of settling time on turbidity removal efficiency

\section{Turbidity Reduction Efficiency of Different Coagulants}

The investigation was done to compare the performance of the PAFS coagulant obtained from aluminium dross leaching with the commercially available polymeric coagulant. Regression analysis was performed on the experimental data, and results showed that the settling time ( $\mathrm{X}$ variable) has a significant influence on turbidity removal rate ( $\mathrm{Y}$ variable) with analysis of variance $\mathrm{P}<0.05$, and therefore $\mathrm{Y}$ variable was predicted for different settling time.

As shown in Figure 7, both coagulants were able to reduce the turbidity of the wastewater, but it was evident that the PAFS coagulant was more effective than the commercially available coagulant. The turbidity removal efficiency of the PAFS coagulant was recorded to be between $75 \%$ to $95 \%$, depending on the settling time. On the other hand, the commercially available polymeric coagulant could only reduce between $41 \%$ to $76 \%$ of the initial turbidity. This result indicates that the combined action of aluminium and iron salts in the PAFS coagulant can remove a broad range of impurities from wastewater, particularly colloidal particles and dissolved organic substances. The addition of these species to wastewater results in colloidal destabilisation due to the interaction with the negatively charged colloidal particles followed by charge neutralisation (Mwewa et al., 2019). 


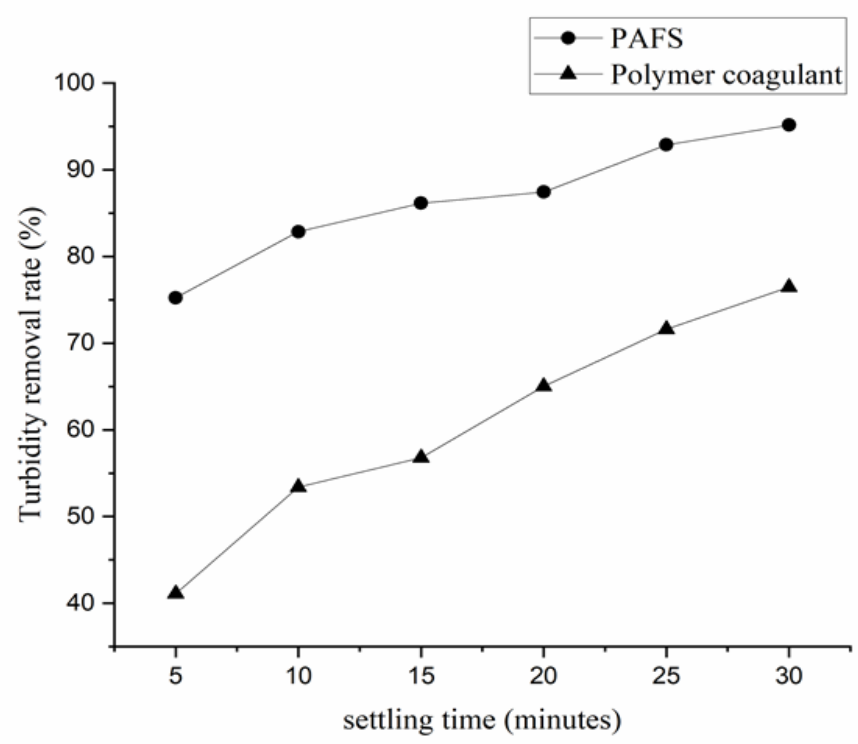

Figure 7. Comparison of turbidity removal efficiency using different coagulants

\section{CONCLUSION}

There is a huge potential to recover alternative coagulants from aluminium dross for wastewater treatment. In this study, acid leaching of aluminium dross was utilised to extract PAFS coagulant from the dross and treatment operations, such as sulfuric acid concentration, leaching temperature and leaching time were considered. The optimum conditions for dissolution of aluminium dross were one mol/L sulfuric acid at $65^{\circ} \mathrm{C}$ and 60 minutes leaching time. The PAFS coagulants prepared under the optimised leaching conditions were then investigated for their coagulation performance. The turbidity removal efficiency was $91.45 \%$ at the optimum coagulant dosage of $0.5 \mathrm{~g}$, raw water $\mathrm{pH}$ of 8 , and 15 minutes settling time. The findings obtained from the present laboratory-scale study may be the basis for the dissolution process on an industrial scale.

\section{ACKNOWLEDGEMENTS}

The authors would like to acknowledge the Master of Environmental Engineering program, Universiti Putra Malaysia under, which this work was funded and completed.

\section{REFERENCES}

Adeosun, S. O., Sekunowo, O. I., Taiwo, O. O., Ayoola, W. A., \& Machado, A. (2014). Physical and mechanical properties of aluminum dross. Advances in Materials, 3(2), 6-10. https://doi.org/10.11648/j. am.20140302.11 
Cao, B., Gao, B., Wang, M., Sun, X., \& Wang, J. (2015). Floc properties of polyaluminum ferric chloride in water treatment: The effect of A1/Fe molar ratio and basicity. Journal of Colloid and Interface Science, 458, 247-254. https://doi.org/10.1016/j.jcis.2015.07.057

Chen, J., Li, X., Cai, W., Shi, Y., Hui, X., Cai, Z., Jin, W., \& Fan, J. (2020). High-efficiency extraction of aluminum from low-grade kaolin via a novel low-temperature activation method for the preparation of poly-aluminum-ferric-sulfate coagulant. Journal of Cleaner Production, 257, Article 120399. https://doi. org/10.1016/j.jclepro.2020.120399

Cui, L., Guo, Y., Wang, X., Du, Z., \& Cheng, F. (2015). Dissolution kinetics of aluminum and iron from coal mining waste by hydrochloric acid. Chinese Journal of Chemical Engineering, 23(3), 590-596. https:// doi.org/10.1016/j.cjche.2014.05.017

Dai, C., \& Apelian, D. (2016). Fabrication and characterization of aluminum dross-containing mortar composites: Upcycling of a waste product. Journal of Sustainable Metallurgy, 3(2), 230-238. https:// doi.org/10.1007/s40831-016-0071-7

Das, B. R., Dash, B., Tripathy, B. C., Bhattacharya, I. N., \& Das, S. C. (2006). Production of $\eta$-alumina from waste aluminium dross. Minerals Engineering, 20(3), 252-258. https://doi.org/10.1016/j. mineng.2006.09.002

David, E., \& Kopac, J. (2013). Aluminum recovery as a product with high added value using aluminum hazardous waste. Journal of Hazardous Materials, 261, 316-324. https://doi.org/10.1016/j.jhazmat.2013.07.042

Elinwa, A. U., \& Mbadike, E. (2011). The use of aluminum waste for concrete production. Journal of Asian Architecture and Building Engineering, 10(1), 217-220. https://doi.org/10.3130/jaabe.10.217

Feng, H., Zhang, G., Yang, Q., Xun, L., Zhen, S., \& Liu, D. (2020). The investigation of optimizing leaching efficiency of Al in secondary aluminum dross via pretreatment operations. Processes, 8(10), Article 1269. https://doi.org/10.3390/pr8101269

Gao, J. Y., Gao, F. Z., Zhu, F., Luo, X. H., Jiang, J., \& Feng, L. (2019). Synergistic coagulation of bauxite residue-based polyaluminum ferric chloride for dyeing wastewater treatment. Journal of Central South University, 26(2), 449-457. https://doi.org/10.1007/s11771-019-4017-7

Jiang, Z., \& Zhu, J. (2021). Preparation, characterization and coagulation performance of a composite coagulant: Polymeric aluminum ferric sulfate. In IOP Conference Series: Earth and Environmental Science (Vol. 647, No. 1, p. 012059). IOP Publishing.

Kim, Y. S., Kim, M. H., \& Yoo, C. K. (2010). A new statistical framework for parameter subset selection and optimal parameter estimation in the activated sludge model. Journal of Hazardous Materials, 183(1-3), 441-447. https://doi.org/10.1016/j.jhazmat.2010.07.044

Lei, G., Ma, J., Guan, X., Song, A., \& Cui, Y. (2009). Effect of basicity on coagulation performance of polyferric chloride applied in eutrophicated raw water. Desalination, 247(1-3), 518-529. https://doi.org/10.1016/j. desal.2008.06.026

Li, A., Zhang, H., \& Yang, H. (2014). Evaluation of aluminum dross as raw material for high-alumina refractory. Ceramics International, 40(8), 12585-12590. https://doi.org/10.1016/j.ceramint.2014.04.069 
Liang, J., Wang, W., Liu, H., Wang, E., Zhong, Y., Li, Y., \& Luo, K. (2020). Optimization of preparation conditions for liquid polymeric ferric sulfate by response surface analysis. Advances in Environmental Protection, 10(01), 85-97. https://doi.org/10.12677/aep.2020.101010

Mahinroosta, M., \& Allahverdi, A. (2018). Enhanced alumina recovery from secondary aluminum dross for high purity nanostructured $\gamma$-alumina powder production: Kinetic study. Journal of Environmental Management, 212, 278-291. https://doi.org/10.1016/j.jenvman.2018.02.009

Mahinroosta, M., \& Allahverdi, A. (2018). Hazardous aluminum dross characterization and recycling strategies: A critical review. Journal of Environmental Management, 223, 452-468. https://doi.org/10.1016/j. jenvman.2018.06.068

Mailar, G., Sreedhara, B. M., Manu, D. S., Hiremath, P., \& Jayakesh, K. (2016). Investigation of concrete produced using recycled aluminium dross for hot weather concreting conditions. Resource-Efficient Technologies, 2(2), 68-80. https://doi.org/10.1016/j.reffit.2016.06.006

Mavinkattimath, R. G., Kodialbail, V. S., \& Govindan, S. (2017). Simultaneous adsorption of Remazol brilliant blue and disperse orange dyes on red mud and isotherms for the mixed dye system. Environmental Science and Pollution Research, 24(23), 18912-18925. https://doi.org/10.1007/s11356-017-9278-9

Mohd-Salleh, S. N. A., Shaylinda, M. Z. N., Othman, N., Yashni, G., \& Norshila, A. B. (2020). Coagulation performance and mechanism of a new coagulant (polyaluminium chloride-tapioca peel powder) for landfill leachate treatment. Journal of Engineering Science and Technology, 15(6), 3709-3722.

Murayama, N., Maekawa, I., Ushiro, H., Miyoshi, T., Shibata, J., \& Valix, M. (2012). Synthesis of various layered double hydroxides using aluminum dross generated in aluminum recycling process. International Journal of Mineral Processing, 110, 46-52. https://doi.org/10.1016/j.minpro.2012.03.011

Mwewa, B., Stopić, S., Ndlovu, S., Simate, G. S., Xakalashe, B., \& Friedrich, B. (2019). Synthesis of polyalumino-ferric sulphate coagulant from acid mine drainage by precipitation. Metals, 9(11), Article 1166. https://oi.org/10.3390/met9111166

Pepper, R. A., Couperthwaite, S. J., \& Millar, G. J. (2016). Comprehensive examination of acid leaching behaviour of mineral phases from red mud: Recovery of Fe, Al, Ti, and Si. Minerals Engineering, 99, 8-18.

Reddy, M. S., \& Neeraja, D. (2016). Mechanical and durability aspects of concrete incorporating secondary aluminium slag. Resource-Efficient Technologies, 2(4), 225-232.

Rivera, R. M., Ulenaers, B., Ounoughene, G., Binnemans, K., \& Van Gerven, T. (2018). Extraction of rare earths from bauxite residue (red mud) by dry digestion followed by water leaching. Minerals Engineering, 119, 82-92. https://doi.org/10.1016/j.mineng.2018.01.023

Sarker, M. S. R., Alam, M. Z., Qadir, M. R., Gafur, M. A., \& Moniruzzaman, M. (2015). Extraction and characterization of alumina nanopowders from aluminum dross by acid dissolution process. International Journal of Minerals, Metallurgy, and Materials, 22(4), 429-436.

Su, X., Li, X., \& Shen, X. (2010). Experimental study on efficient utilization of aluminum ash. Journal of Huazhong Normal University (Natural Sciences),44(2),1000-1190.

Sun, C., Yue, Q., Gao, B., Cao, B., Mu, R., \& Zhang, Z. (2012). Synthesis and floc properties of polymeric ferric aluminum chloride-polydimethyl diallylammonium chloride coagulant in coagulating humic acid-kaolin synthetic water. Chemical Engineering Journal, 185, 29-34. https://doi.org/10.1016/j.cej.2011.04.056 
Sun, Y., Zhu, C., Zheng, H., Sun, W., Xu, Y., Xiao, X., You, Z., \& Liu, C. (2017). Characterization and coagulation behavior of polymeric aluminum ferric silicate for high-concentration oily wastewater treatment. Chemical Engineering Research and Design, 119, 23-32.

Tsakiridis, P. E., Oustadakis, P., \& Agatzini-Leonardou, S. (2013). Aluminium recovery during black dross hydrothermal treatment. Journal of Environmental Chemical Engineering, 1(1-2), 23-32.

Xiao, Y., Reuter, M. A., \& Boin, U. D. O. (2005). Aluminium recycling and environmental issues of salt slag treatment. Journal of Environmental Science and Health, 40(10), 1861-1875. https://doi. org/10.1080/10934520500183824

Yan, L., Wang, Y., Li, J., Shen, H., Zhang, C., \& Qu, T. (2016). Preparation of polymeric aluminum ferric chloride (PAFC) coagulant from fly ash for the treatment of coal-washing wastewater. Desalination and Water Treatment, 57(39), 18260-18274. https://doi.org/10.1080/19443994.2015.1089420

Yang, S., Li, W., Zhang, H., Wen, Y., \& Ni, Y. (2019). Treatment of paper mill wastewater using a composite inorganic coagulant prepared from steel mill waste pickling liquor. Separation and Purification Technology, 209, 238-245.

Zhang, P., \& Ren, B. (2013). Inverse emulsion polymerization of dimethyl diallyl ammonium chloride and acrylamide for water treatment. Asian Journal of Chemistry, 25(7), 3966-3970. https://doi.org/10.14233/ ajchem.2013.13859

Zhang, S., Zhu, W., Li, Q., Zhang, W., \& Yi, X. (2019). Recycling of secondary aluminum dross to fabricate porous $\gamma-\mathrm{Al}_{2} \mathrm{O}_{3}$ assisted by corn straw as biotemplate. Journal of Materials Science and Chemical Engineering, 7(12), 87-102. https://doi.org/10.4236/msce.2019.712010

Zhang, Y., Li, S., Wang, X., \& Li, X. (2015a). Coagulation performance and mechanism of polyaluminum ferric chloride (PAFC) coagulant synthesized using blast furnace dust. Separation and Purification Technology, 154, 345-350. https://doi.org/10.1016/j.seppur.2015.09.075

Zhang, Y., Li, S., Wang, X., Ma, X., Wang, W., \& Li, X. (2015b). Synthesis, purification and characterization of polyaluminum ferric chloride (PAFC) with high $(\mathrm{Al}+\mathrm{Fe}) \mathrm{b}$ content. Separation and Purification Technology, 146, 311-316. https://doi.org/10.1016/j.seppur.2015.03.045

Zhao, H., Liu, H., \& Qu, J. (2011). Aluminum speciation of coagulants with low concentration: Analysis by electrospray ionization mass spectrometry. Colloids and Surfaces A: Physicochemical and Engineering Aspects, 379(1-3), 43-50. https://doi.org/10.1016/j.colsurfa.2010.11.045

Zhao, X., Yang, T., Liu, L., Zhang, X., Fan, L., \& Huang, Y. (2016). Effect of aluminum speciation on silica removal during coagulation of heavy-oil wastewater using polyaluminum chloride. Desalination and Water Treatment, 57(25), 11789-11799. https://doi.org/10.1080/19443994.2015.1044917

Zhu, G., Zheng, H., Zhang, Z., Tshukudu, T., Zhang, P., \& Xiang, X. (2011). Characterization and coagulationflocculation behavior of polymeric aluminum ferric sulfate (PAFS). Chemical Engineering Journal, 178, 50-59. https://doi.org/10.1016/j.cej.2011.10.008 
